\title{
Adolescent Sexuality Education in Nepal: Current Perspectives
}

\author{
Sharmila Pokharel1, Anup Adhikari ${ }^{*}$ \\ ${ }^{1}$ Central Department of Education, Tribhuvan University, Kirtipur, Nepal \\ ${ }^{2}$ Nepal Family Development Foundation and Faculty Member of Public Health, HOPE International College, Lalitpur, Nepal \\ Email: ^ecoanup@gmail.com
}

How to cite this paper: Pokharel, S., \& Adhikari, A. (2021). Adolescent Sexuality Education in Nepal: Current Perspectives. Creative Education, 12, 1744-1754. https://doi.org/10.4236/ce.2021.127132

Received: June 24, 2021

Accepted: July 26, 2021

Published: July 29, 2021

Copyright (c) 2021 by author(s) and Scientific Research Publishing Inc. This work is licensed under the Creative Commons Attribution International License (CC BY 4.0).

http://creativecommons.org/licenses/by/4.0/ (c) (i) Open Access

\begin{abstract}
There is a huge public debate on CSE being amorous and inappropriate. The materials and curriculum for students are considered insufficient and inadequate due to socio-cultural factors, which are deep-rooted in society. Lack of knowledge about sexual and reproductive health and low access to sexual health services have forced young people to engage in unsafe sexual practices in Nepal. Sexuality education should cover lessons on the important role adolescents' sexuality that plays in their personality, positive things that sexuality brings to life, and the role our sexuality plays in connecting an individual with others. Complete sexuality education must be scientifically and age-appropriately precise, culturally competent, and based on people's rights, gender equality, and a positive approach to sexuality and pleasure based that sexuality education affects general health, adaptation to the environment and quality of life and contributes to an optimal life of your choice. Children and teenagers need to get precise clarification about understanding sexuality on how to practice healthy sexual behavior while unhealthy or exploitative risky sexual activity can lead to health and social problems, such as unwanted pregnancy and sexually transmitted infections. The article reviews the current perspectives and situation of CSE among adolescents of Nepal. A review of government documents and research articles has been conducted, and the findings have been synopsized. Consequently, the curriculum developers and policymakers were provided with the recommendations to address common problems that are evitable among adolescents as well as guidelines for teachers' training on related topics.
\end{abstract}

\section{Keywords}

Adolescent, Sexuality Education, Sexual and Reproductive Health, Nepalese Value 


\section{A Holistic Perspective}

Sexuality not only includes sex, gender identities, and roles or sexual orientation, it also determines various dimensions such as eroticism, pleasure, intimacy, and procreation which can be expressed through values, attitude, behavior, and practices. Sexuality can also be experienced through thoughts, fantasies, desires, roles, and relationships. While sexuality can encompass all of these dimensions, not all of them are always experienced or expressed (Connell \& Elliott, 2009; Rose et al., 2019). Various biological, psychological, ethical, legal, historical, religious, and spiritual factors as well as other social, economic, political, and cultural parameters, play together and influence sexuality. Additionally, the skills that adolescents develop through sexuality education are linked to more general life skills such as communication, listening, decision making, negotiation, and learning to ask for help and advice from parents and caregivers (Ismail, Shajahan, Rao, \& Wylie, 2015; Sanabria \& Murray Jr, 2018). These useful life skills are not limited to sexuality but also other aspects of life. They learn to recognize and resist and cope with situations in which they are pressured by others, as well as the long-standing prejudices they face in everyday life (Lucero et al., 2020).

\section{Need for Sexuality Education among Nepalese Adolescents}

Sexuality is a part of the human experience, but sexual health is often ignored, especially when it comes to individuals (Treacy, Taylor, \& Abernathy, 2018). In academic institutions too, the components of sexuality education have sparked considerable debate, such as teaching approach and content covered (Francis, 2019). However, almost one in five young people in the world demonstrates the importance of offering sexuality education for this significant group of population (Francis, 2019).

In 2019, adolescents comprised $18 \%$ i.e. 1.2 billion of the world population, of which $88 \%$ are living in developing countries. Nepal is home to 11 million young people with more than $40 \%$ of the youth aged 16 - 40 years. Of the total population of Nepal, 23.6\% (6.38 million) are adolescents (10 - 19 years) (Napit et al., 2020; Ministry of Health, Nepal, 2000).

The Government of Nepal (GoN) formulated a national health and development strategy in 2000 (Acharya, Van Teijlingen, \& Simkhada, 2009). This strategy guides program planning and implementation which could address improving the health of the adolescents. Hence, adolescents' health is a matter of major concern in Nepal. However, the lack of knowledge about sexual and reproductive health and low access to sexual health services have forced young people to engage in unsafe sexual practices in Nepal (Regmi, Van Teijlingen, Simkhada, \& Acharya, 2010). And due to inadequate sexual and reproductive health knowledge, adolescents are at considerable risk of negative health outcomes (Manu, Mba, Asare, Odoi-Agyarko, \& Asante, 2015). These statistics point out the significance of dealing with adolescents, specifically with the health care needs of this 
sizeable population, especially in developing countries like Nepal.

\section{Adolescent at risk}

Due to the lack of sexuality education, adolescents are susceptible to practicing risky sexual behavior, and it has become a global concern (Haruna, $\mathrm{Hu}, \&$ Chu, 2018; Haruna et al., 2018). Such unsafe sexual activities increase the risk of unwanted pregnancy, STIs, HIV, and AIDS (Regmi, Simkhada, \& Van Teijlingen, 2008). In Nepal, about $17 \%$ of adolescents become mothers between the ages of 15 - 19 years according to the Ministry of Health and Population (MOHP, New ERA, \& ICF, 2017). Thus, due to inadequate sexual and reproductive health knowledge, adolescents are at considerable risk of negative health outcomes (Manu et al., 2015).

Newer literature suggests that adolescents are very likely to be experimenting during adolescence and engage with the types of risky behaviors that have the potential for influencing health quality and probability of short and long-term survival during their lifetime. Hence, primary prevention measures would significantly improve the survival and general health conditions, nutritional status, and sexual and reproductive health of the future Nepalese adult population. Such primary prevention measures include approaches to prevent early pregnancy, unsafe abortions, sexually transmitted diseases, HIV, sexual problems, abuse, and violence.

\section{A cultural challenge}

Adolescents in Nepal are affected by taboos surrounding sexuality which are the main socio-cultural challenges to gain sexual health education. Public debate on issues of a sexual nature is generally regarded as taboo in the Nepalese society, and therefore constitutes an obstacle to providing adequate and effective sexuality education to the Nepalese youth. School-level sexuality education has been receiving strong objections and concerns from most actors of the society, including parents, teachers, politicians, and others, as it is perceived as a sensitive issue to debate. Lawmakers and curriculum developers claim that sexuality education corrupts young people and violates "Nepalese values", leading to promiscuity, experimentation, and irresponsible sexual behavior. These views are at the heart of the traditional Nepalese psyche and should be tentatively approached with psychological insights when challenged (Khatri, Schildbach, Schmitz, Silwal, \& Van Teijlingen, 2013).

The expertise, patience, and time of healthcare professionals are needed to produce a gradual change in the existing conservative attitudes. Until the public demands that sexual health education is designed to prevent morbidity and unintended pregnancies, social agendas will govern much of the policy. There is strong scientific evidence for the cost-effectiveness, outcomes, and cultural relevance of various types of sexuality education in the context of developed and developing countries (Iyer, Clarke, \& Aggleton, 2014). Policymakers and stakeholders should keep scientific evidence at the center of the policy development process and health program planning on youth sexuality education in Nepal. Informed, evidence-based decisions about appropriate sexuality education strat- 
egies and science programs can better serve an emerging young Nepalese population (Janet, n.d.).

Nepal takes pride in its modernization and the next generation will prosper in a much more modern and western climate than today's political and religious leaders (Khatri et al., 2013; Shrestha et al., 2013). Yes, we are linked to our culture, but isn't "science" the "culture" of modernity?

\section{Sexuality education in the classroom}

According to the Sexuality Information and Education Council of the United States, what children can experience through a sexuality education program is an ongoing process of acquiring information and forming attitudes, beliefs, and values. Sexuality education should cover lessons on the important role adolescents' sexuality that plays in their personality, positive things that sexuality brings to life, and the role our sexuality plays in connecting an individual with others. The program/curriculum covers sexual development, sexual and reproductive health, interpersonal relationships, affection, intimacy, body image, and gender roles (Khubchandani, Clark, \& Kumar, 2014).

In Nepal, some schools do not offer sexuality education as it remains a controversial topic, especially given the age at which children should receive such education and the number of details that need to be disclosed. However, some sexuality education studies have also been conducted in Nepal which has focused on adolescent health problems, HIV awareness, premarital sex, sex trafficking, sexual and reproductive health status (Acharya et al., 2009; Adhikari, Uddin, Sapakota, \& Adhikari, 2020; Adhikari, Soonthorndhada, \& Prasartkul, 2009; Regmi et al., 2008), a study by Van Teijlingen and team study in four districts in three regions of the center, the Far West and the Midwest in Nepal, showed that peers, friends, and school appeared to be more important sources of health information for sexual and reproductive health than phones, hotlines, the internet, or religious leader(Van Teijlingen, Simkhada, \& Acharya, 2012).

However, teachers tasked to teach sexuality education face challenges while teaching, such as discomfort and embarrassment when providing information and discussing sexual health with students. Such discomfort and embarrassment among teachers are due to the lack of training and lack of teaching materials to support teachers in their work (Dewart, 2017). Whereas no studies on teaching strategies on sexuality education have been carried out in Nepal, the teaching method of sexuality education has not been properly explored. There are models and methods to measure the level and knowledge of teaching and understanding in the sexuality education classroom which has never been used in Nepal (Janet, n.d.).

Countries holding conservative attitudes towards sexuality education have higher incidences of sexually transmitted diseases in their population and pregnancies among teenagers. In a country like Nepal where sexuality education remains a controversial topic, properly planned interventions are necessary.

\section{A human rights perspective}

Complete sexuality education must be scientifically and age-appropriately 
precise, culturally competent, and based on people's rights, gender equality, and a positive approach to sexuality and pleasure based that sexuality education affects general health, adaptation to the environment and quality of life and contributes to an optimal life of your choice (Bongaarts, Cleland, Townsend, Bertrand, \& Gupta, 2012; UNESCO et al., 2018).

Several conventions on sexual and reproductive health have been organized in Nepal, such as the International Covenant on Economic, Social, and Cultural Rights 1966, the Convention of the Elimination of all Forms of Discrimination Against Women 1979, the Convention on the Rights of the child 1989, the International Conference on Population and Development (ICPD) 1994, Fourth World Conference on Women in Beijing 1995 (Adhikari et al., 2020). Nepal has vowed to fulfill the commitments made in the international realm.

Nepal is also one of the signatories of the 1994 United Nations International Conference for Population and Development (ICPD). To fulfill its commitments, Nepal has committed to offering free and compulsory full sexuality education within the framework of commitments under the ICPD agenda. Therefore, sexuality education was launched between 2002 and 2006 in Nepal with the support of the (United Nations Population Fund) UNFPA (UNFPA, 2014). Nepal introduced comprehensive sexuality education in schools as part of the national curriculum (Pokharel, 2017). The curriculum approach of these schools emphasizes human rights and gender equality and helps students develop the life skills they need to cope with the risk of early marriage and pregnancy (WHO, 2018).

Nepal also participated in the development of the regional strategy for the health and development of young people in 1996 by the WHO Southeast Asia Regional Office (SEARO). And in 1998, young people's Sexual and Reproductive Health (ASRH) was included in Nepal's National Reproductive Health strategy (WHO, 2017).

The Constitution of Nepal has guaranteed rights to women, children, youth, adolescents, and others. Article 39 on the rights of the child in the constitution carries the ethos of strict provisions prohibiting all forms of abuse and violence against children from the family to the community. Recently in August 2018, Parliament passed the Bill Amending and Codifying Children's Laws, which will replace the Children's Law of 1992. The bill stipulates that physical or mental punishment or improper behavior at home, at school, or on any other place called protection, education, or discipline is considered "violence against children" (Niroula, 2018).

The Nepalese government has also taken important operational and legal initiatives to take action against violence against children. The Ministry of Education, Science, and Technology (MOST) has put in place a school-based reporting mechanism, the Suggestion Box, to encourage the reporting of cases of various forms of bullying from colleagues, sexual harassment, and violence between adolescents, also including strong reprimand from teachers (Puri, Tamang, \& Shah, 2011). In addition, 2073 (according to the Nepalese calendar) guidelines of 
the Complaints Response Mechanism of the Center for Education and Staff Development has strictly provisioned that all secondary schools in the country should appoint a teacher as a gender person and create a mandatory suggestion box (Napit et al., 2020; Puri et al., 2011).

\section{A Synopsis of Nepal's National Program on Comprehensive Sexuality Education}

Following the commitments made in the ICPD, Nepal started focusing on improving the sexual and reproductive health sector. National Adolescent Sexual and Reproductive Health Strategy was formulated by the Family Health Division (FHD) - now Family Welfare Division-of the Ministry of Health and Population (WHO, 2017). Following the strategy, the implementation guidelines for ASRH were developed in 2007, and in 2010, the National Adolescent Sexual and Reproductive Health Program was implemented by FHD. In addition, National Adolescent Friendly Health Services (AFHS) standards and actions were developed as required at the programmatic and facility level (Ministry of Health, Nepal, 2000; WHO, 2017).

The Nepal Health Sector Program II Implementation Plan 2010-2015 included the target of introducing 1000 AFHS in the public health system by 2015, thereby covering $25 \%$ of the government health facilities. Although the demand of service and utilization has not been studied the coverage is as per the NHSP plan (Pokharel, 2017; Rijal, 2013).

In 2014, the Ministry of Education and UNFPA commissioned a study to review the status of CSE in Nepal against the six standards set out in the ITGSE UNESC. The study shows the inclusion of CSE topics in lower secondary and secondary levels is encouraging from Grade 6 to 10 even though it is not as comprehensive as given in the ITGSE (UNFPA, 2014). It also revealed that there are notable gaps at the primary school level. The study further showed CSE topics are rarely included in out-of-school programs. The most concerning gap in CSE implementation in Nepal is the scarcity of trained teachers delivering CSE, according to the study. The Government of Nepal has taken many positive steps in support of CSE (Upadhyay, 2016). This includes the establishment of a favorable policy framework; however, challenges do exist. UNFPA is working to support the government in this endeavor (Dewart, 2017).

In Nepal, school students are taught sexual and reproductive health (SRH) through sex education curricula at the secondary level. It covers basic reproductive health facts concerning safe motherhood, family planning, reproductive physiology, STIs, HIV and AIDS, infertility, adolescent health, health problems of postmenopausal women, and reproductive rights. However, little is known as to what extent these contents are practically covered in the classrooms to address the issues of adolescents' sexual health concerns. Thus, an experimental study, referred to as a randomized trial, was conducted by this author to observe the effectiveness of delivering sexual health information to young people in Nepal's secondary schools. The study found that properly developed sex education ses- 
sions led by the health facilitators from external organizations (Primary Health Centers (PHCs) had a big impact on the improvement of quality information and understanding of sexual health for the adolescent compared to the traditional teacher-led sex education program (Dewart, 2017; Rijal, 2013).

Family life education for adolescents addresses two important types of needs: 1) their current normative needs related to changing physical, sexual, cognitive, social, and emotional developments, and 2) their future or emotional needs, future-related to their families prepare for adult roles and responsibilities in marriage and parenthood. In particular, the program covers human sexual anatomy, sexual reproduction, reproductive health, reproductive rights and obligations, emotional relationships, contraception, and different aspects of sexual and non-sexual human behavior (Fentahun, Assefa, Alemseged, \& Ambaw, 2012; Pokharel, Kulczycki, \& Shakya, 2006).

\section{Curriculum's Inconsistency, Insufficiency and Ineffectiveness}

Various strategies and policies have been ratified to address the youth problems recently. Although different policies and strategies are endorsed, there still lie loopholes in schools' teaching methods and understanding techniques. Many young boys and girls still behave in ways that put them at risk of unwanted pregnancy, sexually transmitted diseases, HIV/AIDS, and other kinds of insecurity.

To address the sexual health issues of young people, the Nepalese government has developed a National Youth Health and Development Strategy and programs have been designed and implemented to meet the strategies (Ministry of Health, Nepal, 2000). Based on this strategy, sex education was introduced into the curriculum in Nepal. However, there is evidence that progress has been slow. In Nepal, sex education is offered in lower secondary (grade $6-8$, students ages 11 - 13) and upper secondary (grade 9 - 10, students ages 14 - 15) in the sector Health, Population, and Environment (Acharya, Thomas, \& Cann, 2018). However, a report by UNESCO Nepal argued that material for students of sexuality education was insufficient and inadequate to meet the needs of students. In addition, the design and structure of the current sexuality education curriculum (Hüfner, 2010)-updated in 2018 (UNESCO et al., 2018) appears inconsistent and ineffective in promoting sexual health at the student level (Shrestha et al., 2013). The curriculum approach consists of providing sexuality education in the form of biological facts integrated into a didactic context. There is a lack of comprehensive information on sexual health, social issues, sexual behavior, sexual attitudes, and life skills.

\section{Conclusion}

Sexuality is an integral part of human life. Children and young people have the right to receive reliable, scientifically sound, and comprehensive information about themselves. However, sex education in schools is a sensitive issue. Appro- 
priate sexuality education promotes good values for the children. This leads to better acceptance of who they are. It eliminates children's curiosity about their bodies. Proper sexuality education teaches young children how to protect themselves from abuse. Hence, sexuality education is very essential. In Nepal, children and teenagers need to get precise clarification about understanding sexuality on how to practice healthy sexual behavior while unhealthy or exploitative risky sexual activity can lead to health and social problems, such as unwanted pregnancy and sexually transmitted infections.

Provision of sexual and reproductive health education can directly and/or indirectly help to reduce sexually related diseases. Likewise, sexuality education programs can have a profound impact on increasing the knowledge and understanding of adolescents around the SRH issues.

\section{Acknowledgements}

The authors would like to thank supporters and motivators for writing the article and especially thank Prof. Dr. Ramkirhsna Maharjan for guiding and supporting throughout the process.

\section{Author Contributions}

SP conceptualized content and process and prepared a draft. AA edited the manuscript and participated in revision with SP. Both the authors did agree to submit this paper for publication.

\section{Conflicts of Interest}

The authors declare no conflicts of interest regarding the publication of this paper.

\section{References}

Acharya, D. R., Van Teijlingen, E., \& Simkhada, P. (2009). Opportunities and Challenges in School-Based Sex and Sexual Health Education in Nepal. Kathmandu University Medical Journal, 7, 445-453. https://doi.org/10.3126/kumj.v7i4.2773

Acharya, D., Thomas, M., \& Cann, R. (2018). Nepalese School Students' Views about Sexual Health Knowledge and Understanding. Educational Research, 60, 445-458. https://doi.org/10.1080/00131881.2018.1525304

Adhikari, N., Uddin, S., Sapakota, K. P., \& Adhikari, S. (2020). Sexual and Reproductive Health Needs and Service Utilization among Adolescents in Nepal. American Journal of Public Health Research, 8, 47-53.

Adhikari, R., Soonthorndhada, K., \& Prasartkul, P. (2009). Correlates of Unintended Pregnancy among Currently Pregnant Married Women in Nepal. BMC International Health and Human Rights, 9, Article No. 17.

https://doi.org/10.1186/1472-698X-9-17

Bongaarts, J., Cleland, J. C., Townsend, J., Bertrand, J. T., \& Gupta, M. D. (2012). Executive Summary-Family Planning Programs for the 21st Century: Rationale and Design. Population Council. 
Connell, C., \& Elliott, S. (2009). Beyond the Birds and the Bees: Learning Inequality through Sexuality Education. American Journal of Sexuality Education, 4, 83-102. https://doi.org/10.1080/15546120903001332

Dewart, K. (2017). Investigating Sexuality Education Implementation and Influence in Nepal. http://www.her-choice.org/wp-content/uploads/2018/11/Sexuality-education-Nepa l.pdf

Fentahun, N., Assefa, T., Alemseged, F., \& Ambaw, F. (2012). Parents' Perception, Students' and Teachers' Attitude towards School Sex Education. Ethiopian Journal of Health Sciences, 22, 99-106.

Francis, D. (2019). "Keeping It Straight” What Do South African Queer Youth Say They Need from Sexuality Education? Journal of Youth Studies, 22, 772-790.

https://doi.org/10.1080/13676261.2018.1539223

Haruna, H., Hu, X., \& Chu, S. K. (2018). Adolescent School-Based Sexual Health Education and Training: A Literature Review on Teaching and Learning Strategies. Global Journal of Health Science, 10, 172-183. https://doi.org/10.5539/gjhs.v10n3p172

Hüfner, K. (2010). UNESCO-United Nations Educational, Scientific and Cultural Organization. In A Concise Encyclopedia of the United Nations (pp. 715-718). Brill Nijhoff.

Ismail, S., Shajahan, A., Rao, T. S., \& Wylie, K. (2015). Adolescent Sex Education in India: Current Perspectives. Indian Journal of Psychiatry, 57, 333-337. https://doi.org/10.4103/0019-5545.171843

Iyer, P., Clarke, D., \& Aggleton, P. (2014). Barriers to HIV and Sexuality Education in Asia. Health Education, 114, 118-132. https://doi.org/10.1108/HE-06-2013-0025

Janet, J. G. T. (n.d.). Sexuality and Stigma in Nepal. https://research.ncl.ac.uk/media/sites/researchwebsites/posttraffickinginnepal/Re\%20( Constituting)\%20Identities\%20and\%20Livelihoods.pdf

Khatri, R., Schildbach, E., Schmitz, K., Silwal, P., \& Van Teijlingen, E. (2013). National Adolescent Sexual and Reproductive Health Programme: Mid-Term Evaluation Report. http://eprints.bournemouth.ac.uk/20919/

Khubchandani, J., Clark, J., \& Kumar, R. (2014). Beyond Controversies: Sexuality Education for Adolescents in India. Journal of Family Medicine and Primary Care, 3, 175-179. https://doi.org/10.4103/2249-4863.141588

Lucero, J. E., Hanafi, S. L., Emerson, A. D., Rodriguez, K. I., Davalos, L., \& Grinnell, L. (2020). Sexual Health and Sexual Health Education: Contemporary Perceptions and Concerns of Young Adults within the Millennial Population Cohort. American Journal of Sexuality Education, 15, 476-490. https://doi.org/10.1080/15546128.2020.1832008

Manu, A. A., Mba, C. J., Asare, G. Q., Odoi-Agyarko, K., \& Asante, R. K. (2015). Parent-Child Communication about Sexual and Reproductive Health: Evidence from the Brong Ahafo Region, Ghana. Reproductive Health, 12, Article No. 16. https://doi.org/10.1186/s12978-015-0003-1

Ministry of Health, Nepal (2000). National Adolescent Health and Development Strategy. http://www.fhd.gov.np/index.php/en/2014-03-21-09-41-44/asrh

MOHP (Ministry of Health Ramshah Path), New ERA, \& ICF (International Coaching Federation) (2017). Nepal Demographic and Health Survey 2017.

https://www.dropbox.com/s/9tcmphihqlegny0/2016\%20Nepal\%20DHS\%20Final\%20R eport.pdf? dl $=0$

Napit, K., Shrestha, K. B., Magar, S. A., Paudel, R., Thapa, B., Dhakal, B. R. et al. (2020). 
Factors Associated with Utilization of Adolescent-Friendly Services in Bhaktapur District, Nepal. Journal of Health, Population and Nutrition, 39, Article No. 2. https://doi.org/10.1186/s41043-020-0212-2

Niroula, G. (2018). Trends and Prospects of Social Security Program in Nepal. Nepalese Journal of Insurance and Social Security, 1, 73-85. https://doi.org/10.3126/njiss.v1i1.29864

Pokharel, G. (2017). Reaching Adolescents with Health Services in Nepal. Bulletin of the World Health Organization, 95, 90-91. https://doi.org/10.2471/BLT.17.020217

Pokharel, S., Kulczycki, A., \& Shakya, S. (2006). School-Based Sex Education in Western Nepal: Uncomfortable for Both Teachers and Students. Reproductive Health Matters, 14, 156-161. https://doi.org/10.1016/S0968-8080(06)28255-7

Puri, M., Tamang, J., \& Shah, I. (2011). Suffering in Silence: Consequences of Sexual Violence within Marriage among Young Women in Nepal. BMC Public Health, 11, Article No. 29. https://doi.org/10.1186/1471-2458-11-29

Regmi, P. R., Van Teijlingen, E., Simkhada, P., \& Acharya, D. R. (2010). Barriers to Sexual Health Services for Young People in Nepal. Journal of Health, Population and Nutrition, 28, 619-627. https://doi.org/10.3329/jhpn.v28i6.6611

Regmi, P., Simkhada, P., \& Van Teijlingen, E. (2008). Sexual and Reproductive Health Status among Young Peoples in Nepal: Opportunities and Barriers for Sexual Health Education and Services Utilization. Kathmandu University Medical Journal, 6, 1-5.

Rijal, A. (2013). Revitalization of Primary Health Care in Nepal: A Critical Overview. Health for All, 1, 16-18.

Rose, I. D., Boyce, L., Murray, C. C., Lesesne, C. A., Szucs, L. E., Rasberry, C. N. et al. (2019). Key Factors Influencing Comfort in Delivering and Receiving Sexual Health Education: Middle School Student and Teacher Perspectives. American Journal of Sexuality Education, 14, 466-489. https://doi.org/10.1080/15546128.2019.1626311

Sanabria, S., \& Murray Jr., T. (2018). Infusing Human Sexuality Content and Counseling in Counselor Education Curriculum. American Journal of Sexuality Education, 13, 190-204. https://doi.org/10.1080/15546128.2018.1457461

Shrestha, R. M., Otsuka, K., Poudel, K. C., Yasuoka, J., Lamichhane, M., \& Jimba, M. J. (2013). Better Learning in Schools to Improve Attitudes toward Abstinence and Intentions for Safer Sex among Adolescents in Urban Nepal. BMC Public Health, 13, Article No. 244. https://doi.org/10.1186/1471-2458-13-244

Treacy, A. C., Taylor, S. S., \& Abernathy, T. V. J. (2018). Sexual Health Education for Individuals with Disabilities: A Call to Action. American Journal of Sexuality Education, 13, 65-93. https://doi.org/10.1080/15546128.2017.1399492

UNESCO (United Nations Educational, Scientific and Cultural Organization), UNAIDS (The Joint United Nations Programme on HIV/AIDS), UNFPA (United Nations Population Fund), UNICEF (The United Nations Children's Fund), UN Women, \& WHO (World Health Organization) (2018). International Technical Guidance on Sexuality Education: An Evidence-Informed Approach. UNESCO Publishing.

UNFPA (United Nations Population Fund) (2014). UNFPA Operational Guidance for Comprehensive Sexuality Education: A Focus on Human Rights and Gender. UNFPA (United Nations Population Fund).

Upadhyay, P. (2016). Sexual and Reproductive Health Services: Utilization Pattern of Adolescents in Nepal. The NEHU Journal, 14, 55-67.

Van Teijlingen, E., Simkhada, P., \& Acharya, D. R. (2012). Sexual and Reproductive Health Status and Health Service Utilisation of Adolescents in Four Districts in Nepal.

WHO (World Health Organization) (2017). Adolescent Sexual and Reproductive Health 
Programme to Address Equity, Social Determinants, Gender and Human Rights in Nepal, Report of the Pilot Project. Geneva: World Health Organization.

WHO (World Health Organization) (2018). WHO Recommendations on Adolescent Sexual and Reproductive Health and Rights. Geneva: World Health Organization. 